\title{
Photodynamic therapy of oral Candida infection in a mouse model
}

\author{
Fernanda Freire $^{\mathrm{a}, \mathrm{b}}$, Cleber Ferraresi ${ }^{\mathrm{a}}$, Antonio Olavo C. Jorge ${ }^{\mathrm{b}}$, Michael R. Hamblin ${ }^{\mathrm{a}, \mathrm{c}, \mathrm{d}, *}$ \\ a Wellman Center for Photomedicine, Massachusetts General Hospital, Boston, MA, USA \\ b Department of Biosciences and Oral Diagnosis, Institute of Science and Technology, Universidade Estadual Paulista (UNESP), São José dos Campos, São Paulo, Brazil \\ c Department of Dermatology, Harvard Medical School, Boston, MA, USA \\ ${ }^{\mathrm{d}}$ Harvard-MIT Division of Health Sciences and Technology, Cambridge, MA, USA
}

\section{A R T I C L E I N F O}

\section{Article history:}

Received 7 March 2016

Accepted 30 March 2016

Available online 1 April 2016

\section{Keywords:}

Bioluminescence imaging

Luciferase

Photodynamic therapy

Oral candidiasis

Candida albicans

Biofilm

\begin{abstract}
A B S T R A C T
Species of the fungal genus Candida, can cause oral candidiasis especially in immunosuppressed patients. Many studies have investigated the use of photodynamic therapy (PDT) to kill fungi in vitro, but this approach has seldom been reported in animal models of infection. This study investigated the effects of PDT on Candida albicans as biofilms grown in vitro and also in an immunosuppressed mouse model of oral candidiasis infection. We used a luciferase-expressing strain that allowed non-invasive monitoring of the infection by bioluminescence imaging. The phenothiazinium salts, methylene blue (MB) and new methylene blue (NMB) were used as photosensitizers (PS), combined or not with potassium iodide (KI), and red laser $(660 \mathrm{~nm}$ ) at four different light doses (10 J, $20 \mathrm{~J}$, $40 \mathrm{~J}$ and $60 \mathrm{~J}$ ). The best in vitro $\log$ reduction of $\mathrm{CFU} / \mathrm{ml}$ on biofilm grown cells was: MB plus KI with $40 \mathrm{~J}$ ( $2.31 \mathrm{log}$; $\mathrm{p}<0.001)$; and NMB without KI with $60 \mathrm{~J}(1.77 \log ; \mathrm{p}<0.001)$. These conditions were chosen for treating the in vivo model of oral Candida infection. After 5 days of treatment the disease was practically eradicated, especially using MB plus KI with $40 \mathrm{~J}$. This study suggests that KI can potentiate PDT of fungal infection using MB (but not $\mathrm{NMB}$ ) and could be a promising new approach for the treatment of oral candidiasis.
\end{abstract}

(c) 2016 Elsevier B.V. All rights reserved.

\section{Introduction}

A leading cause of opportunistic infections are fungal species belonging to the Candida genus, with Candida albicans ranking as the most prevalent causative agent of candidiasis and candidemia around the world [1-6]. This trend has been observed over the past decade and is still the case, even in developed countries such as the United States, Denmark, Norway, and Finland [3]. C. albicans is a human commensal organism, and can colonize the skin, mucosal surfaces, gastrointestinal tract and the female genitourinary tract [7]. One important factor that contributes to the pathogenesis of candidiasis is biofilm formation, as C. albicans has the ability to form biofilms on both inert and biological surfaces [8]. These biofilms are typically surrounded by an extracellular polymeric substance [9] which effectively shelters the fungal cells against adverse environmental conditions, including host defense mechanisms and the action of antifungal drugs [10]. Research and development of new antifungal agents is complicated by the paucity of selective microbial targets, since fungi are also eukaryotic cells [11]. In addition, drug resistance of $C$. albicans against antifungals such as azoles and echinocandins represents an increasing problem [12].

\footnotetext{
Abbreviations: PDT, photodynamic therapy; $\mathrm{MB}$, methylene blue; NMB, new methylene blue; PS, photosensitizers; KI, potassium iodide.

* Corresponding author at: BAR414, 40 Blossom St., Boston, MA 02114, USA

E-mail address: hamblin@helix.mgh.harvard.edu (M.R. Hamblin).
}

Therefore, novel antifungal and antibiofilm drugs against these unmanageable infections are urgently needed $[10,11]$. Photodynamic therapy (PDT) has emerged as a promising modality due to its effectiveness against a broad range of species of microorganisms regardless of drug resistance [13]. In this approach, a photosensitizing agent or dye, which is activated by a light source at a specific wavelength in the presence of oxygen, resulting in the production of reactive oxygen species (ROS) and free radicals, is administered into the infected area. These photogenerated ROS disrupt the Candida cytoplasmic membrane and cause an increase in cellular permeability and subsequent damage to intracellular targets. It has been suggested that this oxidative stress might compromise virulence factors of the microorganism, such as the capacity to adhere to host epithelial cells, production of proteinases, reduction of biofilms and formation of germ tubes [14-20].

Mice have been used as models to study oral C. albicans infections and offer some advantages over a rat model in that mice do not harbor Candida spp. in their buccal cavity and therefore do not elicit an adaptive immune response against this yeast $[21,22]$. Optimally, the detection of light from small animals containing bioluminescent cells can be achieved using a charge-coupled device (CCD) based imaging system [23] allowing real-time non-invasive monitoring of the infection.

We have found no studies in the literature that monitored oral C. albicans infections in mice by bioluminescence imaging after use of photodynamic therapy, which could be a therapeutic option for the treatment of oral candidiasis. PDT could be a sole treatment option, or could be used as a coadjuvant to antifungal chemotherapy, improving 
the treatment of oral infections by increasing therapeutic efficacy and by reducing costs.

For these reasons the objective of the present study was to monitor oral candidiasis produced by a luciferase-expressing $C$. albicans strain (CEC 749) in immunosuppressed mice using bioluminescence imaging before and after PDT using four different doses of red light (10 J, $20 \mathrm{~J}$, $40 \mathrm{~J}$ and $60 \mathrm{~J}$ ) with methylene blue or new methylene blue combined or not with potassium iodide to possibly potentiate the PDT effect. We have recently reported that addition of KI could potentiate antimicrobial PDT in vitro and in vivo mediated by MB [24], and also PDT mediated by cationic fullerenes in a mouse model of a wound abrasion infected by Acinetobacter baumannii [25].

\section{Materials and Methods}

\subsection{Ethics Committee}

All animal procedures in this study were approved by the Subcommittee on Research Animal Care (IACUC) of the Massachusetts General Hospital under the protocol (2015N000099) and were in accordance with the guidelines of the National Institutes of Health ( $\mathrm{NIH})$.

\subsection{Cells and Culture Conditions}

A luciferase-expressing C. albicans strain (CEC 749) was used in this study [26]. The luciferase reporter was constructed by fusing a synthetic, codon-optimized version of the Gaussia princeps luciferase gene (gLUC59) to C. albicans PGA59, which encodes a glycosylphosphatidylinositol linked cell wall protein. Luciferase expressed from this PGA59-gLUC fusion was localized at the C. albicans cell surface [26], where it can easily come into contact with its substrate coelenterazine (Gold Biotechnology, Inc., Charlestown, MA, USA) in intact cells. This system allows bioluminescence imaging of $C$. albicans infections after simple addition of coelenterazine solution to the surface of the infected tissue [26]. This approach also allows the detection of luciferase in both hyphae and yeast cells [26,27], given the central importance of the yeast-hyphal transition in C. albicans virulence [28].

C. albicans was routinely grown at $30{ }^{\circ} \mathrm{C}$ on yeast extract-peptonedextrose (YPD) agar and subcultured in YPD medium. The inoculum was prepared by growing the $C$. albicans cells in $3 \mathrm{ml}$ YPD broth overnight at $30{ }^{\circ} \mathrm{C}$ with shaking at $130 \mathrm{rpm}$ in a C24 incubator/shaker (New Brunswick Scientific, Edison, NJ). The broths were then centrifuged at 12,000 rpm for $3 \mathrm{~min}$ (centrifuge 5417 C; Eppendorf, Hamburg, Germany) and resuspended in $0.5 \mathrm{ml}$ of phosphate-buffered saline (PBS) or YPD. The concentrations were then adjusted to the appropriate values for the experiment by measuring the optical density at $570 \mathrm{~nm}$ (OD570) of the C. albicans suspensions, using an Evolution $300 \mathrm{UV}-\mathrm{Vis}$ spectrophotometer (Thermo Scientific). An OD570 of 0.65 correspond to a fungal concentration of $10^{7} \mathrm{CFU} / \mathrm{ml}$ in PBS (in vivo test) or in YPD media (in vitro test).

\subsection{Photosensitizers and Light Source}

The phenothiazinium salts methylene blue (MB) (M9140-25G; Sigma), and new methylene blue (NMB) (556416-1G; Sigma) with or without potassium iodide (KI) were used as PSs in the study. The dye contents of $\mathrm{MB}$ and $\mathrm{NMB}$ were approximately $85 \%$ and $70 \%$, respectively. These photosensitizers were selected by a preliminary study based on the criterion that the concentration produced an effective PDT effect with minimal dark toxicity [29]. Stock PS solutions $(10 \mathrm{mM})$ were prepared by dissolution of the PS powders in sterilized water and were stored in the dark at $4{ }^{\circ} \mathrm{C}$ for no longer than 14 days.

The light source used in this study was emitted by a diode laser ( $\mathrm{Ar}$ royo Instruments, LLC, San Luis Obispo, CA, USA) at a wavelength of $660 \mathrm{~nm}$, at a power of $100 \mathrm{~mW}$, delivering $10 \mathrm{~J}$, or $20 \mathrm{~J}$, or $40 \mathrm{~J}$, or $60 \mathrm{~J}$.
All parameters are given in Table 1. For in vitro experiments, the laser beam was expanded by a lens (model LM2-B) to form a spot diameter $4.7 \mathrm{~cm}$ delivered without contact with the plates (distance of $7 \mathrm{~cm}$ ). For in vivo experiments, the same laser beam was delivered using an optic fiber without a lens, without contact with mouse tongue (distance of $5 \mathrm{~cm}$ ), covering a spot area of $0.38 \mathrm{~cm}^{2}$.

Both the best sets of conditions from in vitro experiments using PDT with $\mathrm{NMB}(\mathrm{NMB} 60 \mathrm{~J})$ and $\mathrm{MB}(\mathrm{MB} / \mathrm{KI} 40 \mathrm{~J}$ ) were chosen to be applied on the in vivo model of oral candidiasis. It is important to highlight that the light parameters were kept the same from the in vitro experiments (wavelength, total power and irradiation time). The optical power reaching the plates (in vitro) and the mouse tongue (in vivo) was measured using an optical energy meter PM100D Thorlabs ${ }^{\circledR}$ fitted with a sensor S310C $\left(3.14 \mathrm{~cm}^{2}\right)$.

\subsection{In vitro Photodynamic Therapy}

In order to grow the biofilms a $250 \mu \mathrm{l}$ aliquot of the suspension ( $10^{7} \mathrm{CFU} / \mathrm{ml}$ in YPD) was pipetted into each well of a 96-well flatbottom microtiter plate. The plate was incubated for $1.5 \mathrm{~h}$ at $30^{\circ} \mathrm{C}$ in a shaker at $75 \mathrm{rpm}$ for the initial adhesion phase. After this period, the wells were washed with $250 \mu$ of PBS to remove loosely adhered cells. A $250 \mu \mathrm{l}$ aliquot of YPD was then pipetted into each washed well, and the plate was incubated at $30{ }^{\circ} \mathrm{C}$ in a shaker at $75 \mathrm{rpm}$ for $48 \mathrm{~h}$. The broth was changed after $24 \mathrm{~h}$. The plate with biofilms formed by C. albicans was then washed with $250 \mu$ of PBS to remove loosely adherent cells.

The biofilm formed by each strain was immersed in $100 \mu \mathrm{l}$ of a solution of each photosensitizer (PS) or PBS for 10 min (pre-irradiation time). Subsequently, the suspended plate was irradiated according to the groups:

- P-L - : received PBS in absence of light. $(n=6)$.

- P- $\mathrm{L}+$ : the effect of the light source only with different doses 10,20 , 40 and $60 \mathrm{~J}$. ( $\mathrm{n}=6$ for each dose).

- P $+\mathrm{L}-$ : the effect of the PS only $[\mathrm{MB}(100 \mu \mathrm{M})$ or NMB $(100 \mu \mathrm{M})$ and these PSs combined with $\mathrm{KI}(100 \mathrm{mM})]$. ( $\mathrm{n}=6$ for each PS).

- P $+\mathrm{L}+$ : treatment with each PS [MB $(100 \mu \mathrm{M})$ or NMB $(100 \mu \mathrm{M})$ and these PSs combined with $\mathrm{KI}(100 \mathrm{mM})]$ and each dose of light (10, $20,40$ and $60 \mathrm{~J})$. ( $\mathrm{n}=6$ for each PS and dose of light).

After this, each well received $100 \mu$ of PBS and the biofilm was disrupted by homogenizing for 1 min using an ultrasonic homogenizer. The suspensions in the wells were considered to be a dilution factor of $10^{-1} .5$ serial dilutions were then made using each original $10^{-1}$ dilution, and aliquots of $10 \mu \mathrm{l}$ were seeded onto YPD agar plates [30] that were then incubated at $30^{\circ} \mathrm{C}$ for $24 \mathrm{~h}$. After the incubation period, the $\mathrm{CFU} / \mathrm{ml}$ values of each plate were determined.

Table 1

Parameters of light for photodynamic therapy (PDT).

\begin{tabular}{ll}
\hline In vitro & In vivo \\
\hline Wavelength $(\mathrm{nm}): 660$ & Wavelength $(\mathrm{nm}): 660$ \\
Pulse frequency: continuous & Pulse frequency: continuous \\
Laser power $(\mathrm{mW}): 100$ & Laser power $(\mathrm{mW}): 100$ \\
Irradiation time $(\mathrm{sec}): 100 / 200 / 400 / 600$ & Irradiation time $(\mathrm{sec}): 400 / 600$ \\
Total energy $(\mathrm{J}): 10 / 20 / 40 / 60$ & Total energy $(\mathrm{J}): 40 / 60$ \\
Energy density $\left(\mathrm{J} / \mathrm{cm}^{2}\right):$ & Energy density $\left(\mathrm{J} / \mathrm{cm}^{2}\right):$ \\
$3.18 / 6.36 / 12.73 / 19.10$ & $105.26 / 157.89$ \\
Power density $\left(\mathrm{mW} / \mathrm{cm}^{2}\right): 31.84$ & Power density $\left(\mathrm{mW} / \mathrm{cm}^{2}\right): 263.15$ \\
Application mode: without contact & Application mode: without contact \\
\hline
\end{tabular}




\subsection{Induction of Experimental Candidiasis}

A total of 15 adult male BALB/c mice (Charles River Laboratories, Wilmington, MA), 7 to 8 weeks old, weighing 17 to $21 \mathrm{~g}$ and with no Candida in their buccal cavities, were used in all experiments. The animals were housed with access to food and water ad libitum and were maintained on a $12 \mathrm{~h}$ light/dark cycle under a room temperature of $21{ }^{\circ} \mathrm{C}$.

The methodology described by Takakura et al. [31] was used to induce experimental candidiasis with some modifications. Briefly, the animals were pre-treated with two separate doses of methylprednisolone acetate (Depo-Medrol, McKesson Medical-Surgical, Inc., Northborough, Boston) in order to create a temporary state of immunosuppression. $150 \mathrm{mg} \mathrm{kg}^{-1}$ of Depo-Medrol were injected intramuscular (i.m.) 1 day before infection with Candida, followed by a second dose of $150 \mathrm{mg} \mathrm{kg}^{-1}$ injected i.m. 3 days after infection with Candida. Tetracycline chloride (Terramicina, Laboratórios Pfizer Ltda., Guarulhos, SP, Brazil) was administered in the drinking water at a concentration of $0.83 \mathrm{mg} / \mathrm{ml}$ beginning 1 day before infection and maintained throughout the experiment. Before $C$. albicans infection, the mice were anesthetized by intraperitoneal (i.p.) injection of a ketamine-xylazine cocktail.

A sterile swab soaked in the C. albicans suspension (luciferase-expressing C. albicans concentration of $10^{7} \mathrm{CFU} / \mathrm{ml}$ in PBS) was used to inoculate the sedated mice by rubbing the swab for $1 \mathrm{~min}$ on the tongue dorsum.

\subsection{In Vivo Photodynamic Therapy}

Twenty-four hours after the second injection of Depo-Medrol, PDT was conducted on the animals under anesthesia produced by intraperitoneal injection of a mixture of ketamine/xylazine $(100 \mathrm{mg} / \mathrm{kg} ; 10: 1$ ratio). The mice were divided into three groups: a) $\mathrm{MB} / \mathrm{KI}+40 \mathrm{~J}+$ : sensitization with $\mathrm{MB}(1 \mathrm{mM})$ with $\mathrm{KI}(1 \mathrm{M})$ and $40 \mathrm{~J}$ of light irradiation $(\mathrm{n}=5)$; b) NMB $+60 \mathrm{~J}+$ : sensitization with NMB $(1 \mathrm{mM})$ without KI combined with $60 \mathrm{~J}$ of light irradiation $(\mathrm{n}=5)$; and $\mathrm{c}) \mathrm{P}-\mathrm{L}-$ : control group not subjected to sensitization with PS or light irradiation $(\mathrm{n}=5)$. The groups "a" and "b" were chosen according to the best results on the in vitro tests.

Before light irradiation, a $10 \mu$ volume of respective PS ( $1 \mathrm{mM}$ ) solution were pipetted onto the tongue dorsum and PS was then incubated for $5 \mathrm{~min}$ in the dark. After this time, the group "a" received $5 \mu \mathrm{l}$ of KI solution (1 M) onto the tongue. The solution of the PS was liquid and although a small amount of the PS had trickled down, the majority of the relatively small drop adhered to the mouse tongue that turned blue before the application of light (Fig. 1). The in vivo dark toxicity of the dye was quantified by bioluminescence imaging. To take these images, $10 \mu \mathrm{l}$ of coelenterazine $(500 \mu \mathrm{g} / \mathrm{ml}$ in 1:9 methanol-PBS; Gold Biotechnology, Inc., St. Louis, MO, USA) [26] were topically smeared onto the surface of each infected tongue. The $10 \%$ methanol present in the solvent was not toxic to the Candida cells. Mice received light exposure of $40 \mathrm{~J}$ or $60 \mathrm{~J}$, according to the group, with bioluminescence imaging taking place after each exposure of light. The light was delivered at an irradiance of $263.15 \mathrm{~mW} / \mathrm{cm}^{2}$ (groups "a" and "b"). The control group ("c") received only coelenterazine in order to carry out the bioluminescence imaging.

To record the time course of the extent of fungal infection, fungal bioluminescence images from the mouse tongue infection was measured daily after each PDT during the 5 days of daily treatment. Euthanasia was performed with an overdose of i.p. injection of a ketaminexylazine cocktail. The tongues were longitudinally cut in half, and onehalf of each organ was fixed in 10\% neutral buffered formalin for $48 \mathrm{~h}$, embedded in paraffin, sectioned ( 5 to $7 \mu \mathrm{m}$ thick), and stained with hematoxylin and eosin (HE) and Periodic Acid-Schiff (PAS) for histologic analysis.

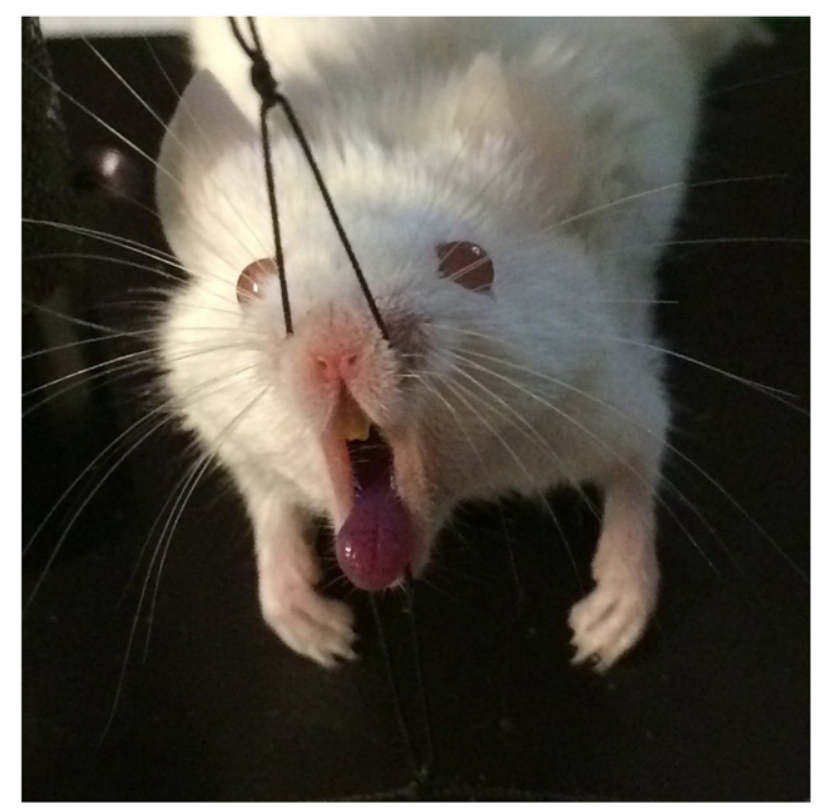

Fig. 1. Mouse tongue turned blue after the application of photosensitizer.

\subsection{Bioluminescence Imaging}

The IVIS® Lumina Series III (PerkinElmer, Inc., Waltham, MA, USA) was used for bioluminescence imaging. Using photon counting mode, an image can be obtained by detecting and integrating individual photons emitted by the fungal cells. Prior to PDT and imaging, mice were anesthetized by i.p. injections of ketamine-xylazine cocktail. Mice were then placed on an adjustable stage in the imaging chamber, and the tongue infected was positioned directly under the camera. A grayscale background image of each tongue was made, and this was followed by a bioluminescence image of the same region displayed in a false-color scale ranging from red (most intense) to blue (least intense) and superimposed on the grayscale image. The signal from the bioluminescence image was quantified as region of interest (ROI) with absolute calibrated data in: photons $\mathrm{s}^{-1} \mathrm{~cm}^{-2} \mathrm{sr}^{-1}$, using the IVIS software.

\subsection{Statistical Analysis}

The data for $\mathrm{CFU} / \mathrm{ml}$ were converted to logarithmic form and analyzed by one-way analysis of variance (ANOVA) and Tukey HSD post hoc test. The $\mathrm{CFU} / \mathrm{ml}$ reduction for $C$. albicans biofilms were calculated comparing each group $(\mathrm{P}+\mathrm{L}-; \mathrm{P}-\mathrm{L}+; \mathrm{P}+\mathrm{L}+)$ and its subgroups, with the control group $(\mathrm{P}-\mathrm{L}-)$.

In a two-dimensional coordinate system, the region of interest (ROI) data, which represent the time courses of fungal luminescence of the tongue infected were calculated using numerical integration. Differences in ROI among the control, NMB $60 \mathrm{~J}$ and MB/KI $40 \mathrm{~J}$ groups in the in vivo study were compared day by day using also ANOVA and Tukey HSD post hoc test. Significance was set at $\mathrm{p}<0.05$.

\section{Results}

Results for the PDT of C. albicans biofilms in vitro using MB or NMB as PSs, with or without addition of KI and the different light doses are shown in Figs. 2, 3, 4 and 5. Only four of twenty groups were not effective $(\mathrm{MB}+10 \mathrm{~J}, \mathrm{MB}+20 \mathrm{~J}, \mathrm{MB}+40 \mathrm{~J}$ and $\mathrm{NMB}+10 \mathrm{~J})$. In all other groups we had a significant reduction. It should be noted that for planktonic cells an antimicrobial effect requires at least $99.9 \%$ of Candida killing. However for biofilms less than 3 logs of killing is needed to be 
Methylene blue

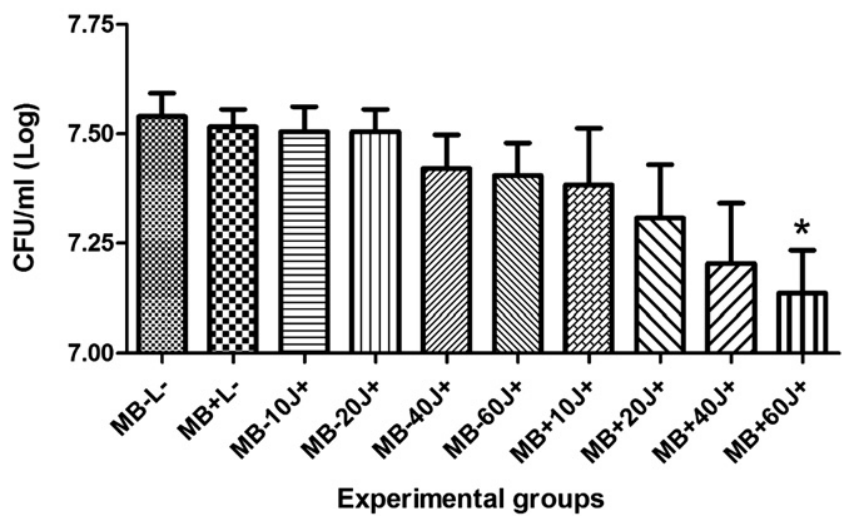

Fig. 2. Mean values and standard deviation of $\mathrm{CFU} / \mathrm{ml}\left(\log _{10}\right)$ of $C$. albicans biofilms exposed to the following treatments: $\mathrm{MB}(100 \mu \mathrm{M})$ with $10,20,40$ or $60 \mathrm{~J}$ of laser doses in comparison with their respective controls, the effect of light alone, the effect of PS alone, and absolute control (no PS, no light). To analyze significance, one-way analysis of variance (ANOVA) and Tukey HSD post hoc test. The CFU/ml reduction for $C$. albicans biofilms were calculated comparing each group $(\mathrm{P}+\mathrm{L}-; \mathrm{P}-\mathrm{L}+; \mathrm{P}+\mathrm{L}+)$ and its subgroups, with the control group $(\mathrm{P}-\mathrm{L}-)$. Values followed by asterisk differed significantly among the experimental conditions $(\mathrm{p}<0.05)$.

antimicrobial. The best log reductions of colony-forming units per milliliter $(\mathrm{CFU} / \mathrm{ml})$ were: $\mathrm{MB}(100 \mu \mathrm{M})$ combined with $\mathrm{KI}(100 \mathrm{mM})$ and $40 \mathrm{~J}$; and NMB $(100 \mu \mathrm{M})$ without KI with $60 \mathrm{~J}$ of irradiation, with log reductions $(\mathrm{p}<0.001)$ of 2.31 and 1.77 , respectively. These two sets of conditions were used in the in vivo infection model.

Fig. 6 shows a comparison among the four treatments used in this study. The group MB plus KI showed significantly more fungal killing compared to $\mathrm{MB}$ alone at all doses of light utilized (10, 20, 40 and $60 \mathrm{~J}$ ) and with NMB alone with 10, 20 and $40 \mathrm{~J}$ of light irradiation. MB plus KI also had a significant difference compared to NMB plus KI with $40 \mathrm{~J}$, and $\mathrm{MB}$ alone had significantly more killing compared to NMB alone when these groups were irradiated with $60 \mathrm{~J}$.

After 4 days of Candida inoculation (day 1 of treatment) a strong positive Candida bioluminescence signal was achieved with the peak occurring after 6 days for the control group (Fig. 7C). In the majority of

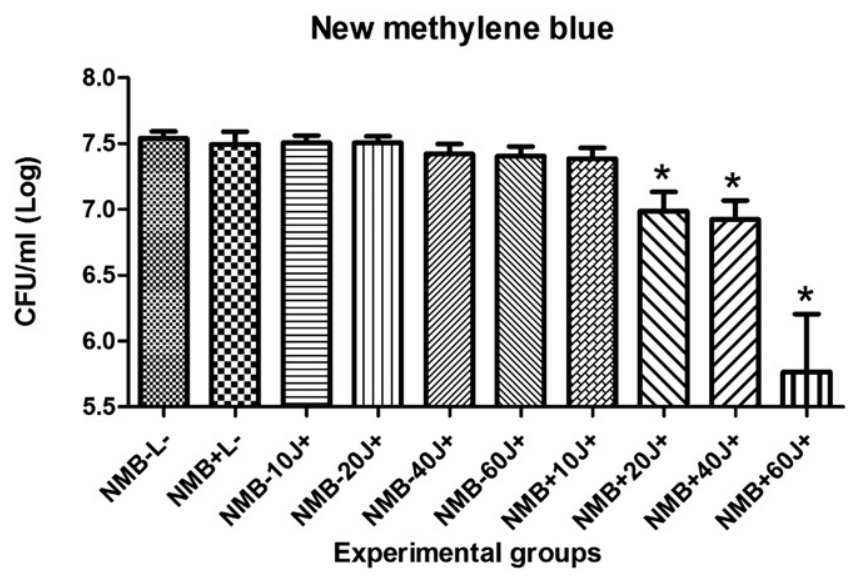

Fig. 4. Mean values and standard deviation of $\mathrm{CFU} / \mathrm{ml}\left(\log _{10}\right)$ of $C$. albicans biofilms exposed to the following treatments: NMB $(100 \mu \mathrm{M})$ with $10,20,40$ or $60 \mathrm{~J}$ of laser doses in comparison with their respective controls, the effect of light alone, the effect of PS alone, and absolute control (no PS, no light). To analyze significance, one-way analysis of variance (ANOVA) and Tukey HSD post hoc test. The CFU/ml reduction for C. albicans biofilms were calculated comparing each group $(\mathrm{P}+\mathrm{L}-; \mathrm{P}-\mathrm{L}+; \mathrm{P}+\mathrm{L}+$ ) and its subgroups, with the control group $(\mathrm{P}-\mathrm{L}-)$. Values followed by asterisk differed significantly among the experimental conditions $(\mathrm{p}<0.05)$.

animals subjected to immunosuppression and Candida inoculation, white lesions typical of pseudomembranous candidiasis were observed (Fig. 7A).

Total loss of bioluminescence signal was seen in two animals on the fifth day of treatment (Fig. 7B) with NMB $(1 \mathrm{mM})$, as can be seen in the example in Fig. 7C. Fig. 7D shows that both PSs were effective on the treatment of oral candidiasis. No difference was found between the two PSs ( $p>0.05$ for all days of treatment).

A representative set of periodic-acid-Schiff (PAS) and hematoxylin and eosin (HE) stained images from the infected tongue on day 5 post infection are shown in Fig. 8. These images demonstrated the presence of numerous $C$. albicans cells in the form of yeast and multicellular hyphal filaments in the control group. While all yeast cells were located on the surface of the keratinized epithelial layer of the tongue, the hyphal filaments branched out in every direction into the tissue. A host

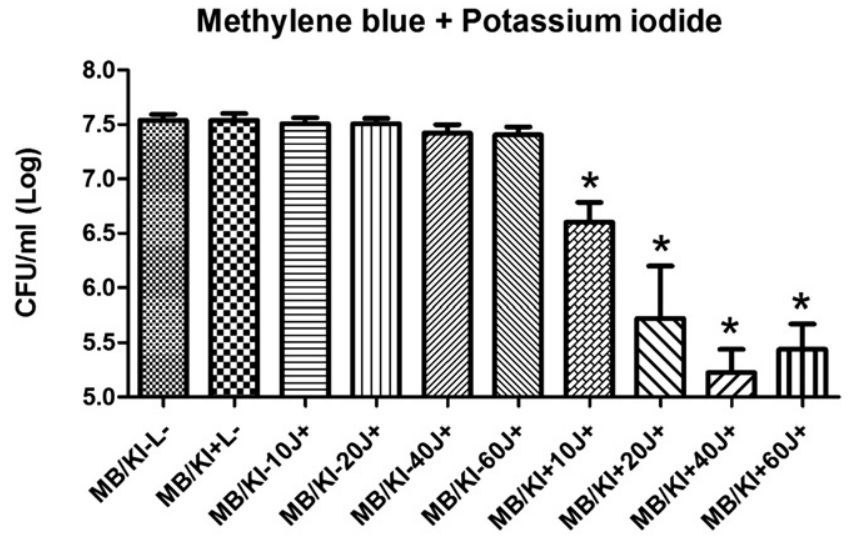

Experimental groups

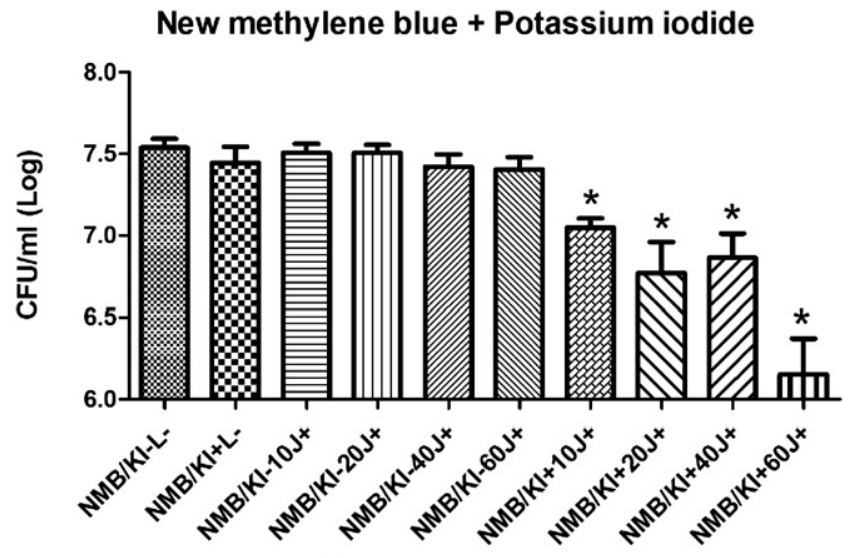

Experimental groups

Fig. 3. Mean values and standard deviation of $\mathrm{CFU} / \mathrm{ml}\left(\log _{10}\right)$ of $C$. albicans biofilms exposed to the following treatments: $\mathrm{MB}(100 \mu \mathrm{M})$ combined with $\mathrm{KI}(100 \mathrm{mM})$ and 10 , 20,40 or $60 \mathrm{~J}$ of laser doses in comparison with their respective controls, the effect of light alone, the effect of PS alone, and absolute control (no PS, no light). To analyze significance, one-way analysis of variance (ANOVA) and Tukey HSD post hoc test. The $\mathrm{CFU} / \mathrm{ml}$ reduction for $C$. albicans biofilms were calculated comparing each group $(\mathrm{P}+\mathrm{L}-$ $; \mathrm{P}-\mathrm{L}+; \mathrm{P}+\mathrm{L}+)$ and its subgroups, with the control group $(\mathrm{P}-\mathrm{L}-)$. Values followed by asterisk differed significantly among the experimental conditions $(\mathrm{p}<0.05)$.

Fig. 5. Mean values and standard deviation of $\mathrm{CFU} / \mathrm{ml}\left(\log _{10}\right)$ of $C$. albicans biofilms exposed to the following treatments: $\mathrm{NMB}(100 \mu \mathrm{M})$ combined with $\mathrm{KI}(100 \mathrm{mM})$ and $10,20,40$ or $60 \mathrm{~J}$ of laser doses in comparison with their respective controls, the effect of light alone, the effect of PS alone, and absolute control (no PS, no light). To analyze significance, one-way analysis of variance (ANOVA) and Tukey HSD post hoc test. The $\mathrm{CFU} / \mathrm{ml}$ reduction for $C$. albicans biofilms were calculated comparing each group $(\mathrm{P}+\mathrm{L}-$ $; \mathrm{P}-\mathrm{L}+; \mathrm{P}+\mathrm{L}+)$ and its subgroups, with the control group $(\mathrm{P}-\mathrm{L}-)$. Values followed by asterisk differed significantly among the experimental conditions $(\mathrm{p}<0.05)$. 
PDT in vitro

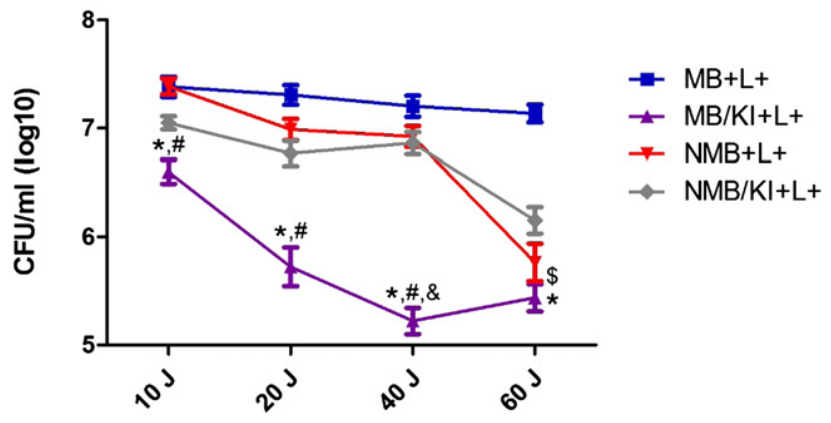

Fig. 6. Mean values and standard deviation of $\mathrm{CFU} / \mathrm{ml}\left(\log _{10}\right)$ of $C$. albicans biofilms exposed to the following treatments: $\mathrm{MB}(100 \mu \mathrm{M}), \mathrm{MB}(100 \mu \mathrm{M})$ combined with $\mathrm{KI}$ $(100 \mathrm{mM}), \mathrm{NMB}(100 \mu \mathrm{M})$ and NMB $(100 \mu \mathrm{M})$ combined with $\mathrm{KI}(100 \mathrm{mM})$; all treated with 10,20, 40 or 60 J of laser light. To analyze significance, a ANOVA and Tukey HSD post hoc test were used. Values followed by asterisk had difference between MB and MB plus KI, values followed by hash had difference between NMB and MB plus KI, values followed by "\&" had difference between MB plus KI and NMB plus KI and values followed by "\$” had difference between MB and NMB. $(\mathrm{p}<0.05)$.

response to $C$. albicans infection, characterized by an inflammatory infiltrate, was also observed. Several lesions in the epithelial tissue were also observed, including epithelial hyperplasia, basal cell layer disorganization, exocytosis, loss of filiform papillae, hyperkeratosis and intraepithelial micro abscesses development. The figure also demonstrated that in the PDT treated groups the surfaces of the tongue appeared intact showing well-defined layers without visible yeasts or hyphal filaments, and without any lesions in the epithelial tissue.

\section{Discussion}

C. albicans is the most frequent fungal species isolated from superficial and invasive fungal infections and systemic infections are associated with high rates of mortality. Since there is an increasing number of strains of this microorganism that are resistant to antifungal agents, studies are needed to evaluate the effect of photodynamic therapy on oral candidiasis infections. In this study, we used a low light imaging charge-coupled device (CCD) camera to non-invasively monitor the results in real time. The treatment of candidiasis continues to be a challenge in dentistry. In this respect, photodynamic therapy has shown promising results as a coadjuvant treatment for this disease.

Schelenz et al. [32] isolated 269 strains of Candida spp. from the buccal cavity of patients with hematological malignancies or head and neck solid tumors. The authors evaluated the sensitivity profile of these strains to antifungal agents and found resistance to fluconazole (4.5\%), itraconazole (11.7\%), ketoconazole (11.3\%), voriconazole $(0.75 \%)$, and caspofungin (41.1\%); however, all strains were susceptible to amphotericin B. Thus, amphotericin B has been used in treatment of Candida infections caused by fluconazole-resistant strains; however, amphotericin B can have substantial side effects, and a few cases of resistance have been reported [33]. For these reasons PDT is a new approach being developed for the treatment of candidiasis and the aim of this study was to study the effects of PDT both in vitro and in vivo.

Zhang et al. [25] synthesized C60-fullerene (LC16) bearing a decaquaternary chain and deca-tertiary-amino groups that facilitated electron-transfer reactions via the photoexcited fullerene. Addition of the harmless salt, potassium iodide (KI) $(10 \mathrm{mM})$ potentiated the ultraviolet A (UVA) or white light-mediated killing of Gram-negative bacteria A. baumannii, Gram-positive methicillin-resistant Staphylococcus aureus and fungal yeast $C$. albicans by 1-2 + logs. A mouse model of a skin abrasion infected with bioluminescent $A$. baumannii gave increased loss of bioluminescence when iodide (10 mM) was combined with LC16 and UVA/white light. In a study from the same group, Vecchio et al. [24] added KI to MB and observed a consistent increase of red light-mediated bacterial killing of Gram-positive and Gram-negative species in vitro and in vivo. In vivo, they also observed less bacterial recurrence in wounds in the days post-treatment. They proposed that the mechanism of action was probably due to formation of reactive iodine species that

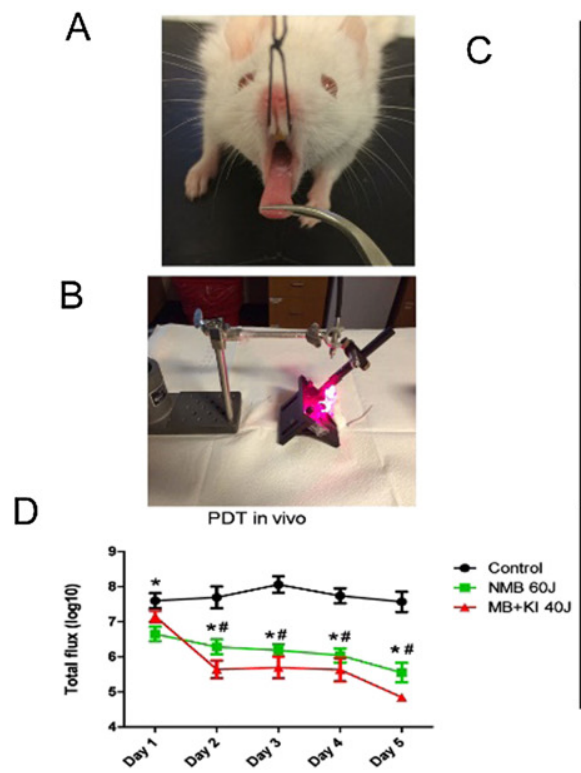

\begin{tabular}{|c|c|c|c|c|c|}
\hline & Day 1 & Day 2 & Day 3 & Day 4 & Day 5 \\
\hline Control & & & & & \\
\hline $\mathrm{MB}+\mathrm{KI}+40 \mathrm{~J}$ & & & & & \\
\hline NMB+60J & & & & & \\
\hline
\end{tabular}

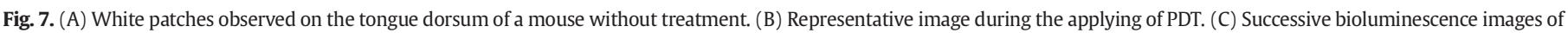

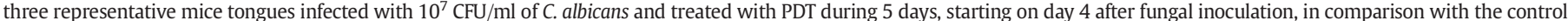

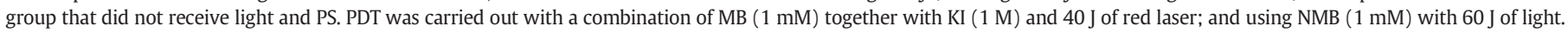

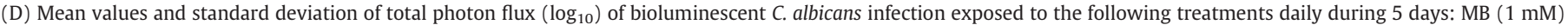

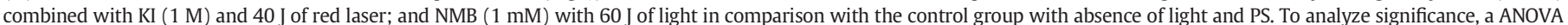

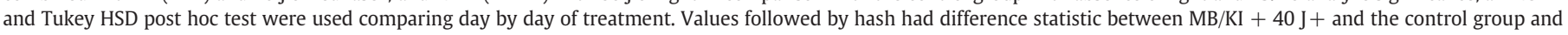
values followed by asterisk had significant difference between $\mathrm{NMB}+60 \mathrm{~J}+$ and the control group $(\mathrm{p}<0.05)$. 


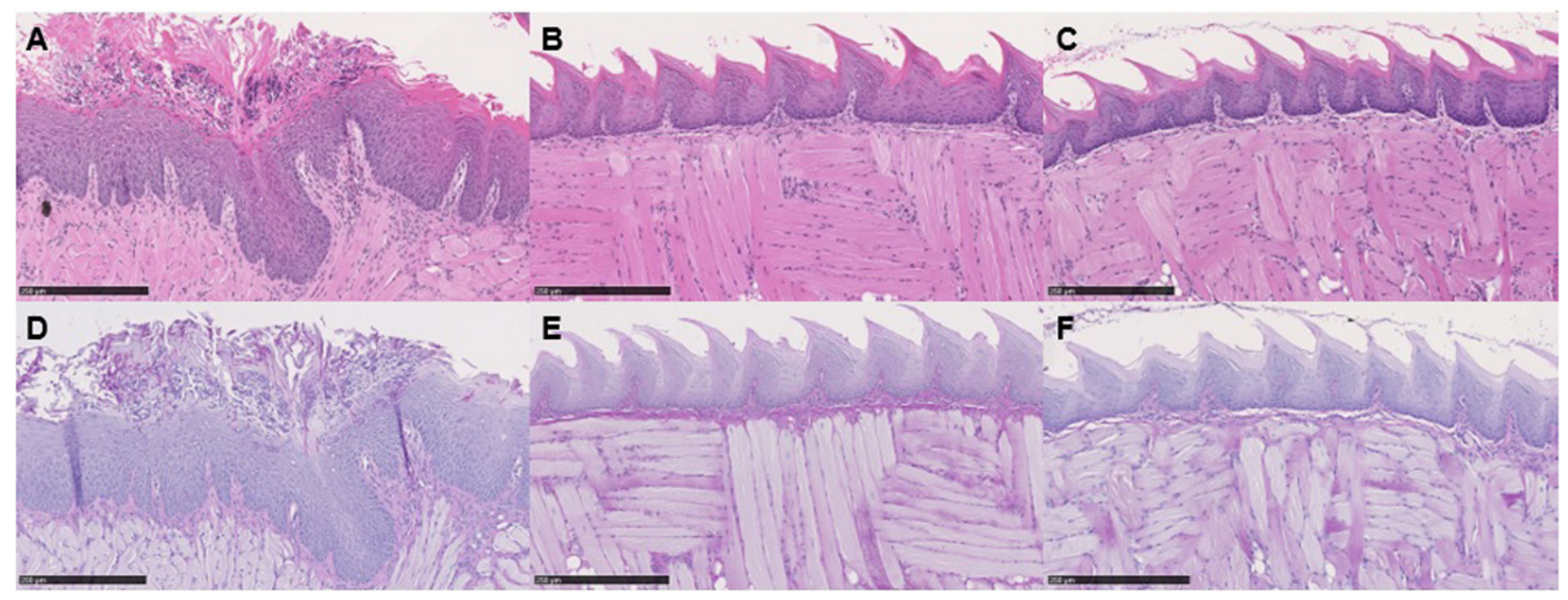

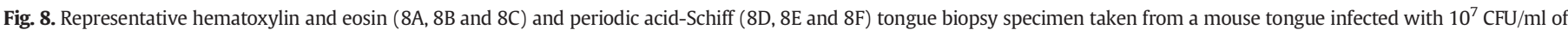

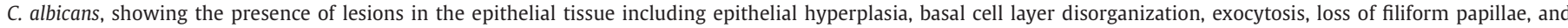

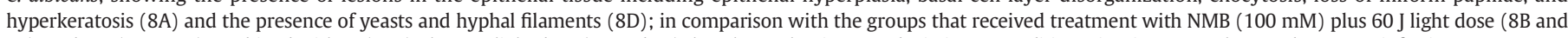

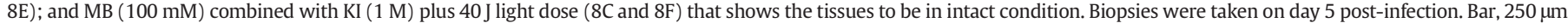

are produced quickly with a short lifetime. In our study MB $(100 \mu \mathrm{M})$ was combined with $\mathrm{KI}(100 \mathrm{mM})$ and four different doses of light (10, 20,40 and $60 \mathrm{~J}$ ) against $C$. albicans biofilms grown in vitro. When MB was used without KI the best log reduction was found with $60 \mathrm{~J}$ of light energy while the $\mathrm{MB} / \mathrm{KI}$ solution achieved 2.31 of log reduction with $40 \mathrm{~J}$ of irradiation. This last result was the best one in all in vitro tests of our study and was chosen to apply to the oral Candida infection.

Freire et al. [34] compared Rose Bengal (RB) with Eosin Y (2,4,5,7 tetrabromofluorescein) assessing their potency for photoinactivation of $C$. albicans biofilms. After culturing these biofilms for $48 \mathrm{~h}$, treatment was done with $200 \mu \mathrm{M}$ RB or Eosin Y for 5 min as a pre-irradiation period and subsequent illumination with a green LED (90 mW; $532 \pm$ $10 \mathrm{~nm}$ ) for $180 \mathrm{~s}$ (light dose: $42.63 \mathrm{~J} / \mathrm{cm} 2$; applied energy: $16.2 \mathrm{~J}$ ), which resulted in inactivation rates of 0.22 and $0.45 \log _{10}$ for $\mathrm{RB}$ and Eosin Y, respectively. In our study MB had much better log reduction on CFU/ml of C. albicans biofilms as described above. We also tested another phenothiazinium dye NMB $(100 \mu \mathrm{M})$ combined or not with $\mathrm{KI}$ (100 mM) with four doses of red laser $(10,20,40$ and $60 \mathrm{~J})$. When NMB was combined with KI the highest log reduction was 1.38 with $60 \mathrm{~J}$ of light energy, but the best log reduction was found with this PS without any added $\mathrm{KI}\left(1.77 \log _{10}\right)$ and with $60 \mathrm{~J}$ of irradiation as well. This group $(\mathrm{NMB}+60 \mathrm{~J}+)$ was also chosen to use in the in vivo study, which showed promising results. A possible explanation for the observation that KI potentiated PDT with MB but not with NMB lies with consideration of the photochemical mechanisms carried out by the two dyes. The production of iodine radicals from iodide anion represents a one-electron transfer reaction, and it is possible that MB carries out more electron transfer reactions (Type I photochemical mechanism), while NMB may carry out more singlet oxygen generation (Type II photochemical mechanism). This hypothesis would require further investigation to confirm it.

Khademi et al. [35] induced oral candidiasis, using C. albicans isolated from an azole-resistant patient, with a similar protocol to ours and at 2 days after the last immunosuppression injection, PDT was carried out on the tongue dorsum by use of different concentrations of MB or polyL-lysine-chlorine (e6) conjugate (pL-ce6) as PSs, followed by a $10 \mathrm{~min}$ diode laser illumination at $660 \mathrm{~nm}(n=6$ each). The most effective PS found in the animals treated with PDT mediated by MB at a concentration of $450 \mathrm{mg} / \mathrm{L}$ with reduction from $3.43 \log _{10}$ to 0 (CFU/ml) and it was the highest $C$. albicans eradication recorded among all groups in this study.
Costa et al. [36] and Dovigo et al. [37] also worked with a model of oral candidiasis using PDT treatment post infection. The first study used erythrosine $(400 \mu \mathrm{mol} / \mathrm{L})$ followed by exposure to a green LED ( $14.34 \mathrm{~J} \mathrm{~cm}^{-2}$ ) and the quantified ( $\mathrm{CFU} / \mathrm{ml}$ ) yeasts recovered from the mice were significantly reduced by $0.73 \log _{10}$. This group also analyzed the tongues microscopically and found the presence of yeasts and hyphae that were limited to the keratinized layer on the tongue dorsum, which was primarily localized on simple conic papillae. Several lesions in the epithelial tissue were also observed and in the areas with tissue lesions, the lamina propria exhibited a mild inflammatory infiltrate. The groups that received PDT demonstrated a reduction of yeasts, hyphae, lesions and inflammatory infiltrate. The second study used curcumin $(20,40$ and $80 \mu \mathrm{M})$ and illumination with LED light and all animals exposed to curcumin with LED light exhibited a significant reduction in C. albicans viability after PDT, but the use of $80 \mu \mathrm{M}$ curcumin and light was able to induce the highest $\log _{10}$ reduction in colony counts ( 4 logs) and no evidence of fungi was found on histological examination of the tongues in four animals treated with PDT, with $80 \mu \mathrm{M}$ curcumin.

In contrast to the last 3 studies cited, the aim of our study was to evaluate PDT of oral candidiasis using real-time bioluminescence monitoring. The use of a luciferase-expressing strain of $C$. albicans allowed this real-time monitoring using bioluminescence imaging with an IVIS $®$ Lumina Series III. In our study we found that 5 days of daily PDT treatment with $\mathrm{MB}(1 \mathrm{mM})$ combined with $\mathrm{KI}(1 \mathrm{M})$ and $40 \mathrm{~J}$ of light irradiation and NMB with $60 \mathrm{~J}$ of light energy almost eradicated the infection (Fig. 7C and D). On day 1 of treatment only the group NMB $+60 \mathrm{~J}+$ was significantly reduced in comparison with the control group $(\mathrm{p}=$ 0.012). On day 2 however both PDT groups were significantly reduced, $\mathrm{p}=0.006$ for NMB and $\mathrm{p}<0.001$ for MB. From the third day both PSs had $\mathrm{p}<0.001$ when the treatment with these PSs was compared with the control group. During the 5 days of treatment no difference was found between the treatments with $\mathrm{MB}$ and $\mathrm{NMB}$ ( $\mathrm{p}>0.05$ for all days). Observing Figs. 6 and 7D we can see that the treatment with MB plus KI was the best one among the four treatments tested in this study, and this combination with $40 \mathrm{~J}$ of irradiation was chosen for the animal experimental group.

Under optical microscopy, many yeasts and hyphae, epithelial lesions such as epithelial hyperplasia, basal cell layer disorganization, exocytosis, loss of filiform papillae, hyperkeratosis and intraepithelial micro abscess development, and mild inflammatory infiltrate with a 
predominance of neutrophils were observed on the tongue dorsum of the animals without treatment with $\mathrm{MB}$ or NMB (Fig. 8A and D). In some cases, moderate inflammatory infiltrate and mononuclear cells in the lamina propria and basal layer were observed, and congested vessels were occasionally noted. On the tongues of the animals that received PDT treatment, we found only occasional yeasts, hyphae, lesions and inflammatory infiltrate. Most of the tongues of the animals that were treated were uninjured (Fig. 8B, C, E and F) demonstrating that PDT with MB (1 mM) combined with KI $(1 \mathrm{M})$ and 40 J of light irradiation and NMB with $60 \mathrm{~J}$ of light energy is effective.

Judging by the results obtained in the present study, both NMB-PDT and MB-PDT combined with KI represents two potential antifungal strategies to treat oral candidiasis in an immunosuppressed murine model. A single application of PDT was sufficient to produce elimination of $C$. albicans from some of the evaluated mice $(\mathrm{NMB}+60 \mathrm{~J}+)$ but the most promising results were observed with the use of 5 days of daily treatment using either PS, suggesting that PDT using our protocols is a promising approach for treatment of oral candidiasis. Considering the non-toxic nature of KI (FDA approved and generally available as a health supplement to avoid iodine deficiency) clinical trials studies using PDT combined with KI could be undertaken to translate our results into clinical practice.

\section{Acknowledgments}

This work was supported by the Fundação de Amparo à Pesquisa do Estado de São Paulo (FAPESP), Brazil (Scholarship 2014/25772-9). CF was supported by CNPq, Conselho Nacional de Desenvolvimento Científico e Tecnológico (Scholarship 202313/2014-0) and Lemann Foundation; MR Hamblin was supported by US NIH grant R01AI050875.

\section{References}

[1] M. Pfaller, D. Neofytos, D. Diekema, N. Azie, H.U. Meier-Kriesche, S.P. Quan, D. Horn, Epidemiology and outcomes of candidemia in 3648 patients: data from the Prospective Antifungal Therapy (PATH Alliance(R)) registry, 2004-2008, Diagn. Microbiol. Infect. Dis. 74 (4) (2012) 323-331, http://dx.doi.org/10.1016/j.diagmicrobio.2012. 10.003.

[2] H. Wisplinghoff, J. Ebbers, L. Geurtz, D. Stefanik, Y. Major, M.B. Edmond, R.P. Wenzel, H. Seifert, Nosocomial bloodstream infections due to Candida spp. in the USA: species distribution, clinical features and antifungal susceptibilities, Int. J. Antimicrob. Agents 43 (1) (2014) 78-81, http://dx.doi.org/10.1016/j.ijantimicag.2013.09.005.

[3] J. Guinea, Global trends in the distribution of Candida species causing candidemia, Clin. Microbiol. Infect.: the official publication of the European Society of Clinical Microbiology and Infectious Diseases 20 (Suppl. 6) (2014) 5-10, http://dx.doi.org/10. 1111/1469-0691.12539.

[4] M. Bassetti, M. Merelli, F. Ansaldi, D. de Florentiis, A. Sartor, C. Scarparo, A. Callegari, E. Righi, Clinical and therapeutic aspects of candidemia: a five year single centre study, PLoS One 10 (5) (2015), e0127534, http://dx.doi.org/10.1371/journal.pone. 0127534.

[5] M. Nucci, F. Queiroz-Telles, T. Alvarado-Matute, I.N. Tiraboschi, J. Cortes, J. Zurita, M. Guzman-Blanco, M.E. Santolaya, L. Thompson, J. Sifuentes-Osornio, J.I. Echevarria, A.L. Colombo, Epidemiology of candidemia in Latin America: a laboratory-based survey, PLoS One 8 (3) (2013), e59373, http://dx.doi.org/10.1371/journal.pone. 0059373.

[6] I. Das, P. Nightingale, M. Patel, P. Jumaa, Epidemiology, clinical characteristics, and outcome of candidemia: experience in a tertiary referral center in the UK, Int. J. Infect. Dis.: IJID: official publication of the International Society for Infectious Diseases 15 (11) (2011) e759-e763, http://dx.doi.org/10.1016/j.ijid.2011.06.006.

[7] D.M. Underhill, I.D. Iliev, The mycobiota: interactions between commensal fungi and the host immune system, Nat. Rev. Immunol. 14 (6) (2014) 405-416, http://dx.doi. org/10.1038/nri3684.

[8] S.M. Seddiki, Z. Boucherit-Otmani, K. Boucherit, D. Kunkel, [Fungal infectivities of implanted catheters due to Candida sp. Biofilms formation and resistance], J. Mycol. Med. 25 (2) (2015) 130-135, http://dx.doi.org/10.1016/j.mycmed.2015.03. 003.

[9] G. Ramage, S.P. Saville, D.P. Thomas, J.L. Lopez-Ribot, Candida biofilms: an update, Eukaryot. Cell 4 (4) (2005) 633-638, http://dx.doi.org/10.1128/EC.4.4.633-638. 2005.

[10] C.G. Pierce, J.L. Lopez-Ribot, Candidiasis drug discovery and development: new approaches targeting virulence for discovering and identifying new drugs, Expert Opin. Drug Discov. 8 (9) (2013) 1117-1126, http://dx.doi.org/10.1517/17460441. 2013.807245.

[11] C.G. Pierce, A. Srinivasan, P. Uppuluri, A.K. Ramasubramanian, J.L. Lopez-Ribot, Antifungal therapy with an emphasis on biofilms, Curr. Opin. Pharmacol. 13 (5) (2013) 726-730, http://dx.doi.org/10.1016/j.coph.2013.08.008.
[12] H.T. Taff, K.F. Mitchell, J.A. Edward, D.R. Andes, Mechanisms of Candida biofilm drug resistance, Future Microbiol 8 (10) (2013) 1325-1337, http://dx.doi.org/10.2217/ fmb.13.101.

[13] T. Dai, Y.Y. Huang, M.R. Hamblin, Photodynamic therapy for localized infectionsstate of the art, Photodiagn. Photodyn. Ther. 6 (3-4) (2009) 170-188, http://dx. doi.org/10.1016/j.pdpdt.2009.10.008.

[14] L.N. Dovigo, A.C. Pavarina, E.G. Mima, E.T. Giampaolo, C.E. Vergani, V.S. Bagnato, Fungicidal effect of photodynamic therapy against fluconazole-resistant Candida albicans and Candida glabrata, Mycoses 54 (2) (2011) 123-130, http://dx.doi.org/ 10.1111/j.1439-0507.2009.01769.x.

[15] S. Martins Jda, J.C. Junqueira, R.L. Faria, N.F. Santiago, R.D. Rossoni, C.E. Colombo, A.O. Jorge, Antimicrobial photodynamic therapy in rat experimental candidiasis: evaluation of pathogenicity factors of Candida albicans, Oral Surg. Oral Med. Oral Pathol. Oral Radiol. Endod. 111 (1) (2011) 71-77, http://dx.doi.org/10.1016/j.tripleo.2010. 08.012 .

[16] E. Munin, L.M. Giroldo, L.P. Alves, M.S. Costa, Study of germ tube formation by Candida albicans after photodynamic antimicrobial chemotherapy (PACT), J. Photochem. Photobiol. B Biol. 88 (1) (2007) 16-20, http://dx.doi.org/10.1016/j. jphotobiol.2007.04.011.

[17] M.P. Cormick, M.G. Alvarez, M. Rovera, E.N. Durantini, Photodynamic inactivation of Candida albicans sensitized by tri- and tetra-cationic porphyrin derivatives, Eur. J. Med. Chem. 44 (4) (2009) 1592-1599, http://dx.doi.org/10.1016/j.ejmech.2008.07. 026.

[18] L.M. Giroldo, M.P. Felipe, M.A. de Oliveira, E. Munin, L.P. Alves, M.S. Costa, Photodynamic antimicrobial chemotherapy (PACT) with methylene blue increases membrane permeability in Candida albicans, Lasers Med. Sci. 24 (1) (2009) 109-112, http://dx.doi.org/10.1007/s10103-007-0530-2.

[19] B.M. Soares, D.L. da Silva, G.R. Sousa, J.C. Amorim, M.A. de Resende, M. Pinotti, P.S. Cisalpino, In vitro photodynamic inactivation of Candida spp. growth and adhesion to buccal epithelial cells, J. Photochem. Photobiol. B Biol. 94 (1) (2009) 65-70, http://dx.doi.org/10.1016/j.jphotobiol.2008.07.013.

[20] A.C. Costa, V.M. de Campos Rasteiro, C.A. Pereira, E.S. da Silva Hashimoto, M. Beltrame Jr., J.C. Junqueira, A.O. Jorge, Susceptibility of Candida albicans and Candida dubliniensis to erythrosine- and LED-mediated photodynamic therapy, Arch. Oral Biol. 56 (11) (2011) 1299-1305, http://dx.doi.org/10.1016/j.archoralbio.2011.05. 013.

[21] J.R. Naglik, P.L. Fidel Jr., F.C. Odds, Animal models of mucosal Candida infection, FEMS Microbiol. Lett. 283 (2) (2008) 129-139, http://dx.doi.org/10.1111/j.1574-6968. 2008.01160.x

[22] Y.H. Samaranayake, L.P. Samaranayake, Experimental oral candidiasis in animal models, Clin. Microbiol. Rev. 14 (2) (2001) 398-429, http://dx.doi.org/10.1128/ CMR.14.2.398-429.2001.

[23] T.N. Demidova, F. Gad, T. Zahra, K.P. Francis, M.R. Hamblin, Monitoring photodynamic therapy of localized infections by bioluminescence imaging of genetically engineered bacteria, J. Photochem. Photobiol. B Biol. 81 (1) (2005) 15-25, http:// dx.doi.org/10.1016/j.jphotobiol.2005.05.007.

[24] D. Vecchio, A. Gupta, L. Huang, G. Landi, P. Avci, A. Rodas, M.R. Hamblin, Bacterial photodynamic inactivation mediated by methylene blue and red light is enhanced by synergistic effect of potassium iodide, Antimicrob. Agents Chemother. 59 (9) (2015) 5203-5212, http://dx.doi.org/10.1128/AAC.00019-15.

[25] Y. Zhang, T. Dai, M. Wang, D. Vecchio, L.Y. Chiang, M.R. Hamblin, Potentiation of antimicrobial photodynamic inactivation mediated by a cationic fullerene by added iodide: in vitro and in vivo studies, Nanomedicine (London) 10 (4) (2015) 603-614, http://dx.doi.org/10.2217/nnm.14.131.

[26] B. Enjalbert, A. Rachini, G. Vediyappan, D. Pietrella, R. Spaccapelo, A. Vecchiarelli, A.J. Brown, C. d'Enfert, A multifunctional, synthetic Gaussia princeps luciferase reporter for live imaging of Candida albicans infections, Infect. Immun. 77 (11) (2009) 4847-4858, http://dx.doi.org/10.1128/IAI.00223-09.

[27] C. d'Enfert, A. Vecchiarelli, A.J. Brown, Bioluminescent fungi for real-time monitoring of fungal infections, Virulence 1 (3) (2010) 174-176, http://dx.doi.org/10.4161/viru. 1.3.11119.

[28] S. Biswas, P. Van Dijck, A. Datta, Environmental sensing and signal transduction pathways regulating morphopathogenic determinants of Candida albicans, Microbiol. Mol. Biol. Rev.: MMBR 71 (2) (2007) 348-376, http://dx.doi.org/10. 1128/MMBR.00009-06

[29] T. Dai, V.J. Bil de Arce, G.P. Tegos, M.R. Hamblin, Blue dye and red light, a dynamic combination for prophylaxis and treatment of cutaneous Candida albicans infections in mice, Antimicrob. Agents Chemother. 55 (12) (2011) 5710-5717, http://dx.doi. org/10.1128/AAC.05404-11.

[30] S. Park, H. Chibli, J. Nadeau, Solubilization and bio-conjugation of quantum dots and bacterial toxicity assays by growth curve and plate count, J. Vis. Exp.: JoVE 65 (2012), e3969, http://dx.doi.org/10.3791/3969.

[31] N. Takakura, Y. Sato, H. Ishibashi, H. Oshima, K. Uchida, H. Yamaguchi, S. Abe, A novel murine model of oral candidiasis with local symptoms characteristic of oral thrush, Microbiol. Immunol. 47 (5) (2003) 321-326.

[32] S. Schelenz, S. Abdallah, G. Gray, H. Stubbings, I. Gow, P. Baker, P.R. Hunter, Epidemiology of oral yeast colonization and infection in patients with hematological malignancies, head neck and solid tumors, J. Oral Pathol. Med.: official publication of the International Association of Oral Pathologists and the American Academy of Oral Pathology 40 (1) (2011) 83-89, http://dx.doi.org/10.1111/j.1600-0714.2010.00937.x.

[33] L.P. Samaranayake, W. Keung Leung, Jin L (2009) oral mucosal fungal infections, Periodontology 49 (2000) 39-59, http://dx.doi.org/10.1111/j.1600-0757.2008.00291.x.

[34] F. Freire, A.C. Costa, C.A. Pereira, M. Beltrame Junior, J.C. Junqueira, A.O. Jorge, Comparison of the effect of rose bengal- and eosin Y-mediated photodynamic inactivation on planktonic cells and biofilms of Candida albicans, Lasers Med. Sci. 29 (3) (2014) 949-955, http://dx.doi.org/10.1007/s10103-013-1435-x. 
[35] H. Khademi, N. Torabinia, M. Allameh, H.R. Jebreilamtigh, Comparative evaluation of photodynamic therapy induced by two different photosensitizers in rat experimental candidiasis, Dent. Res. J. 11 (4) (2014) 452-459.

[36] A.C. Costa, V.M. Campos Rasteiro, E.S. da Silva Hashimoto, C.F. Araujo, C.A. Pereira, J.C. Junqueira, A.O. Jorge, Effect of erythrosine- and LED-mediated photodynamic therapy on buccal candidiasis infection of immunosuppressed mice and Candida albicans adherence to buccal epithelial cells, Oral Surg. Oral Med. Oral Pathol. Oral Radiol. 114 (1) (2012) 67-74, http://dx.doi.org/10.1016/j.00oo.2012.02.002.

[37] L.N. Dovigo, J.C. Carmello, C.A. de Souza Costa, C.E. Vergani, I.L. Brunetti, V.S. Bagnato A.C. Pavarina, Curcumin-mediated photodynamic inactivation of Candida albicans in a murine model of oral candidiasis, Med. Mycol. 51 (3) (2013) 243-251, http://dx. doi.org/10.3109/13693786.2012.714081. 